Revistade
Economì
Contemporâned

\title{
INDÚSTRIA BANCÁRIA BRASILEIRA: EVIDÊNCIA DA FORMAÇÃO DE INSTITUIÇÕES FINANCEIRAS MULTINACIONAIS
}

\author{
Armando João Dalla Costa ${ }^{a}$ \\ Elson Rodrigo de Souza-Santos ${ }^{b}$ \\ aProfessor do Departamento de Economia e do Programa de Pós-Graduação em Desenvolvimento \\ Econômico da Universidade Federal do Paraná (UFPR). \\ ${ }^{\text {b}}$ Estudante do Doutorado em Economia pela Universidade de São Paulo (USP).
}

Artigo recebido em 26/02/2013 e aprovado em 22/09/2014.

RESUMO: Neste trabalho, o objetivo é caracterizar o movimento de internacionalização e formação de multinacionais bancárias brasileiras. Para isso, buscou-se identificar se a indústria bancária do país apresenta condições para criar esse tipo de conglomerado financeiro e quais são as instituições líderes e os primeiros passos rumo à internacionalização. Em seguida, discutem-se os fatores propulsores e inibidores do movimento de expansão e internacionalização. Os resultados indicam que tais processos existem, e as instituições envolvidas são o Banco do Brasil, Itaú/Unibanco e Bradesco. Os fatores propulsores são identificados como solidez institucional, reestruturação bancária dos anos 1990 - que deu solidez e forçou as instituições a repensarem seus negócios - e, o momento favorável da economia brasileira com o fortalecimento do mercado interno. Como inibidores surgem o risco gerado pela incerteza e instabilidade provocado pela crise financeira de 2008 que ainda não possui um desdobramento previsível.

PALAVRAS-CHAVE: Integração financeira; internacionalização; multinacionais bancárias.

CLASSIFICAÇÃO JEL: G21; G34; F20.

Correspondência Armando João Dalla Costa.

E-mal: ajdcosta@uol.com.br. 


\section{REFLECTIONS ON THE BRAZILIAN BANKING INDUSTRY: EVIDENCE OF THE FORMATION OF MULTINATIONAL FINANCIAL INSTITUTIONS}

ABSTRACT: The present paper discusses the process of internationalization and the emergence of Brazilian multinational banks. For this matter we discuss whether the banking industry has created prosperous conditions to financial conglomerates develop, identifies the leading institutions in the country, and describe the first steps taken towards internationalization. The paper also discusses the incentives and inhibitors to the international expansion of Brazilian banks. The results indicate that Bank of Brazil, Itaú/Unibanco and Bradesco are leaders. Incentive factors are the institutional robustness, the economic restructuring that took place in the 1990s and gave strength to national banks, and the momentum of Brazil's economy due to a stronger domestic market. Inhibitors are the threats posed by the uncertainty and the instability due to the financial crisis of 2008, with an unpredictable unfolding.

KEYWORDS: Financial integration; internationalization; multinational bank.

\section{INTRODUÇÃO}

Na última década, a expansão internacional das instituições financeiras brasileiras voltou à pauta, especialmente em relação aos grandes bancos, apresentando-se como uma oportunidade de explorar novos mercados e ganhar musculatura para se transformarem em conglomerados financeiros internacionais. Uma das evidências foi a justificativa dada pelo presidente-executivo do grupo Itaú/Unibanco, Roberto Setúbal, em 2008, na cerimônia do anúncio da fusão das instituições homônimas de que “(...) nós [o Brasil] precisamos de um banco internacional (...)” (Salles, 2008). Outra foi o programa internacional do Banco do Brasil, que foi traduzido em negócios, como a parceria com Bradesco e o português Banco Espírito Santo (BES) para conquistar os mercados não bancarizados africanos, fechada em 2008, e a aquisição do argentino Banco Patagônia, em 2010.

O fenômeno de formação de multinacionais bancárias não é propriamente um movimento novo no Brasil. Nas décadas de 1960 e 1970, Bradesco e Banco do Brasil despontavam como instituições com vocação internacional. O destaque, naquela ocasião, era do Banco do Brasil que, apesar de incorporar funções públicas, firmava-se como uma multinacional bancária. Esta perspectiva foi aprofundada na gestão de Nestor Jost (1967-1974) que adotou uma estratégia agressiva de expansão internacional, implantação de agências e bases de operações ao redor do mundo, inclusive com atuação no mercado de euromoedas e banco de investimento (Banco do Brasil, 2010) Entretanto, a crise da década de 1980 seguida da abertura/reestruturação do sistema bancário brasileiro na década seguinte ceifou o movimento de internacionalização trazendo o foco para o mercado interno.

Neste trabalho, o objetivo será caracterizar o movimento de internacionalização e formação de multinacionais bancárias brasileiras ao buscar evidências sobre a existência do fenômeno. Em seguida, objetiva-se identificar os fatores propulsores e inibidores. Cabe ressaltar que os atores principais são os grandes bancos em relação à transferência das atividades bancárias, isto é, operações que resultem da aquisição de instituições, parcerias ou construção de redes para atender os mercados locais. A justificativa para a opção das principais instituições é identificar e materializar movimentos que outros bancos menores podem seguir, tanto pela facilidade nas esferas financeiras quanto em produtos específicos ${ }^{1}$.

Desconsideramos a introdução do Banco Nacional de Desenvolvimento Econômico e Social (BNDES) de outros bancos e de órgãos de fomento, por fazerem parte de políticas de Estado e não funcionarem dentro de uma lógica de mercado em busca de lucro. Desta forma, não se encaixa no tipo de banco e forma de internacionalização proposta no artigo. 
As atenções da maioria dos trabalhos em relação à internacionalização do sistema voltam-se para os efeitos da entrada de instituições estrangeiras sobre o mercado interno, derivado da abertura, reestruturação e privatização a partir dos anos 1990. Tal evidência manifesta-se em dois momentos: em um primeiro, pela aquisição de bancos nacionais e, mais recentemente, com a injeção de recursos para os bancos estabelecidos. Sobre o tema podemos citar trabalhos, como os de Carvalho et al. (2002), Corazza e Oliveira (2007), que abordam a chamada "desnacionalização bancária". Por outro lado, autores como Costa (2010), ainda que em uma apresentação, começam a desprender atenção sobre a possibilidade da formação de multinacionais bancárias nacionais capazes de competir no exterior.

Preliminarmente, as conclusões indicam que o movimento de formação de multinacionais bancárias nacionais procede. Entretanto, ainda é inicial e prematuro dizer quais os rumos serão tomados nos próximos anos, tendo como protagonistas o Banco do Brasil, o Itaú/Unibanco e o Bradesco. Os fatores propulsores são identificados como: i) solidez institucional da formação dos bancos brasileiros; ii) abertura/reestruturação/choque de competição na década de 1990 que forçou as instituições a repensarem seu negócio; e iii) momento favorável da economia brasileira e forte mercado interno. Por outro lado, os inibidores estão baseados no risco gerado pela incerteza e instabilidade emergida com a crise financeira de 2008, que ainda não possui um desdobramento previsível e afeta diretamente a indústria bancária.

O trabalho está organizado em três blocos. O primeiro apresenta uma visão geral a respeito da reestruturação e internacionalização bancária nos tempos recentes. $\mathrm{O}$ segundo caracteriza o movimento de formação das multinacionais bancárias brasileiras buscando fatos que evidenciem a procedência do objeto de estudo. Por último e mais importante, os motivos propulsores e inibidores a respeito da internacionalização no contexto brasileiro.

\section{PANORAMA DO NEGÓCIO E INTERNACIONALIZAÇÃO BANCÁRIA}

Na segunda metade do século XX, o sistema bancário e suas instituições sofreram grandes transformações derivadas da mudança de cenário de atuação. Destacam-se a liberalização e a desregulamentação financeira a partir dos anos 1960/1970, permitindo e forçando a reinvenção do negócio bancário. Em seguida vieram o movimento de internacionalização bancária e a formação de mega-conglomerados financeiros multinacionais de atuação global.

\subsection{DINÂMICA DO NEGÓCIO BANCÁRIO}

No pós-1945 o negócio bancário começou a deixar de ser apenas a intermediação entre poupadores e tomadores de fundos operando em um ambiente altamente regulamentado para, gradualmente, ver-se livre das amarras legais e explorar novos mercados e produtos. Segundo Dymski (1999), as mudanças levaram a reinvenção do negócio bancário em nome da sobrevivência das instituições colocando como focos a criação de novos mercados, segmentação de clientes, exploração de novos produtos, serviços e potencialidade das inovações financeiras.

As conclusões de Dymski (1999) estão baseadas nas transformações da indústria bancária norte-americana na última metade do século XX. O ponto inicial da análise foram as reformas da década de 1930, durante a presidência de Roosevelt, quando o sistema bancário foi segmentado e regulamentado como resposta à crise bancária que se seguiu à Grande Depressão. Entretanto, nos anos 1960/1970 a liberalização e a desregulamentação financeira começaram a ascender levando as instituições a ganharem maior liberdade para gerir o próprio negócio e, como uma empresa não financeira, buscar novos mercados e visando aumentar seus lucros.

$\mathrm{Na}$ Europa e em outras regiões, a estrutura bancária baseada em bancos múltiplos (ou universais) não foi abandonada e facilitou a transformação em conglomerados financeiros ao longo do tempo, à medida que a liberalização avançava. Para Rich e Walter (1993), os bancos múltiplos foram bem vistos devido a: i) vantagens competitivas derivadas da diversificação; ii) pequenos bancos múltiplos tenderem a ter melhor capacidade de sobrevivência; e iii) na forma como aparecem, os bancos universais não serem os únicos, permitindo maior flexibilidade.

Entretanto, a liberalização e a desregulamentação financeira impulsionaram o movimento de consolidação (ou concentração) bancária contribuindo para a formação de trustes bancários com elevado poder de mercado e atuação internacional. Em números, a quantidade de fusões e aquisições saltou de oito para 46 entre os anos de 1990 e 1999 representando, respectivamente, US\$26,5 e 291 bilhões (Tabela 1).

\section{Tabela 1 - Fusões e aquisições do setor financeiro de 1990 a 1999}

\begin{tabular}{lclcllrrrrr}
\hline & $\mathbf{1 9 9 0}$ & $\mathbf{1 9 9 1}$ & $\mathbf{1 9 9 2}$ & $\mathbf{1 9 9 3}$ & $\mathbf{1 9 9 4}$ & $\mathbf{1 9 9 5}$ & $\mathbf{1 9 9 6}$ & $\mathbf{1 9 9 7}$ & $\mathbf{1 9 9 8}$ & $\mathbf{1 9 9 9}$ \\
\hline Números de Fusões e Aquisições & 8 & 10 & 6 & 11 & 14 & 23 & 21 & 49 & 58 & 46 \\
Valor (em US\$ bi) & 26,5 & 22,1 & 12,4 & 39,7 & 23,7 & 113 & 59 & 223 & 431 & 291 \\
\hline
\end{tabular}

Fonte: BIS (2000, p. 34)

Para Berger et al. (1999), o resultado foi elevar o poder de mercado e/ou aumentar a eficiência do sistema de pagamentos e instituições, maior competição e ampliar a 
gama de serviços e inovações financeiras. De outro lado, Dymski (1999, p. 50-51) aponta três razões para a defesa da consolidação bancária: i) bancos fortes podem absorver os mais fracos prevenindo crises; ii) cresce a segurança e diversificação de mercados; e iii) aumenta a produtividade por meio das economias de escala e escopo.

Nos Estados Unidos, Mishkin (1998) verificou a redução do número de instituições financeiras e a proliferação de redes bancárias interestaduais, um fenômeno novo para o mercado historicamente fragmentado. Em números, entre 1930 e 1980 a quantidade de bancos comerciais nos EUA girava em torno de 13-15 mil, mas entre $1980 \mathrm{e}$ 1995 caiu para nove, atingindo cinco mil, nos anos recentes.

Na Europa, Dermine (2002) observa que as bases para a integração econômica e viabilização da moeda única, o euro, passava por criar um mercado bancário único que proporcionasse maior eficiência e competitividade. Segundo Chick e Dow (1997), o resultado foi a destruição das estruturas bancárias nacionais, bem como a reestruturação ou o desaparecimento dos bancos locais e regionais favorecendo o fortalecimento de grandes bancos pan-europeus como o espanhol Santander e o britânico HSBC. Entretanto, Dermine (2002) é cético em relação ao objetivo principal e questiona se realmente conseguiu-se atingir e criar um mercado unificado.

Outro aspecto foi a redução do tamanho do Estado pela privatização e reestruturação dos bancos estatais, justificadas pela busca de eficiência, mercados financeiros e créditos melhor ajustados. Entretanto, Micco et al. (2005) observam que a presença do Estado no setor bancário mundial permanece alta. Nos países industrializados, cerca de um quarto dos empréstimos era concedido por instituições com alguma participação estatal e, nas nações em desenvolvimento, a participação chegava a metade. Porém, o aspecto estatal não significa, necessariamente, ineficiência, má administração ou prejuízo, mas sim que o Estado possui um papel fundamental para liderar o crescimento, desenvolvimento econômico e políticas de crédito e estabilidade da indústria bancária.

\subsection{MOVIMENTO DE INTERNACIONALIZAÇÃO}

O colapso do padrão ouro nos anos 1970 representa, segundo Eichengreen (2004), a abertura para um novo arranjo internacional baseado em moeda sem lastro, câmbio flutuante e afrouxamento das regras no sistema financeiro no nível nacional e internacional. Para Abdelal e Ruggie (2009), o cenário impulsionou o crescimento massivo dos mercados financeiros globais integrados endossado pela argumentação da melhor alocação de recursos e redução de riscos.

Segundo Dages et al. (2000), acompanhada da liberalização ocorreu a abertura dos mercados nacionais justificada pela facilidade de acesso a fundos estrangeiros, capaci- dade de atração de capitais, estabilidade macroeconômica, competição e eficiência das instituições e do sistema como um todo. Adicionalmente, a operação de bancos estrangeiros no mercado local funciona como garantia de estabilidade devido à facilidade em recorrer a recursos das matrizes para evitar a falta de liquidez.

Sobre a operacionalização da internacionalização bancária, Germidis e Michalet (1984) distinguiram três esferas: a primeira, baseada na supervisão que consiste no apoio a clientes nos mercados estrangeiros; a segunda, na esfera financeira com a operação de crédito e suporte às instituições, às empresas e aos governos locais; a terceira, no deslocamento das atividades bancárias levando as instituições estrangeiras a atuarem e competirem nos mercados locais. Antes da mudança estrutural dos anos 1970, a primeira e a segunda formas eram dominantes e lideradas pelos bancos norte-americanos e japoneses. Posteriormente, ganhou força a terceira forma devido à abertura dos mercados nacionais, tomando a liderança as instituições europeias.

No aspecto teórico, as primeiras abordagens foram dadas pelos trabalhos de Grubel (1977) e Aliber (1984) inspirados nas teorias de investimento direto oriundas de Kindleberger (1969). A base do pensamento era que as multinacionais bancárias são mais eficientes e capazes de atender as novas demandas de serviços oriundos do investimento direto das multinacionais não-financeiras. Assim, como observa Paula (2003), as instituições buscariam investir em países para preservar a relação com o cliente e se aproveitar da maior eficiência em relação às instituições locais. A base de construção desta visão teórica foi o movimento de internacionalização das empresas norte-americanas pós-1945, sendo acompanhadas pelos bancos nacionais.

Entretanto, trabalhos empíricos recentes começaram a questionar a lógica das teorias antecessoras e buscar novos caminhos tendo como foco os efeitos no mercado bancário, sistema financeiro e instituições, unindo aspectos macro, meso e microeconômico. Entre os novos autores podemos citar Focarelli e Pozzolo (2000) que realizaram um estudo sobre os países da Organização para a Cooperação e o Desenvolvimento Econômico (OCDE) a respeito das características e estratégias de internacionalização bancária. Os resultados indicam que fatores como grau de integração econômica busca por lucro e expansão de mercados são determinantes para justificar a internacionalização. Deminguc-Kunt e Huizinga (1998) enfatizam o papel da eficiência para explicar as vantagens competitivas de bancos estrangeiros sobre as instituições locais, considerando que a lucratividade é influenciada por diferentes fatores como impostos, estrutura financeira, legal e institucional. No estudo de Berger et al. (2000) foram examinadas duas hipóteses: as instituições nacionais possuem inúmeras vantagens de conhecimento (por exemplo, cultura e legislação) e as internacionais, sobressaem-se porque são mais eficientes e diversificadas. A conclusão é nebulosa porque as vantagens variam de país para país. Mesmo assim, indicam que os bancos tendem a escolher 
países mais simpáticos e fáceis de compreender a lógica do mercado e seus marcos regulatórios.

$\mathrm{Na}$ introdução, citamos que como conclusões preliminares o movimento de formação de multinacionais bancárias brasileiras guarda semelhança com o movimento dos bancos europeus, especialmente, os espanhóis. Em razão da ênfase dada à formação de mega-instituições em busca de oportunidades no mercado internacional, forte estrutura institucional e mercado interno colocaram o deslocamento das atividades bancárias como fundamentais para a estratégia. No caso da Espanha, Sebastián e Hemansanz (2000) enfatizam o planejamento para a integração europeia nos anos 1980, acompanhada do incentivo à concentração e à formação de grandes grupos empresarias em áreas estratégias capazes de competir globalmente. Entre as áreas contempladas estava a indústria bancária, levando a uma estratégia estatal premeditada de criar concentração no setor, tendo como vitoriosos o Santander e o Bilbao Vizcaya.

De outro lado, nos anos 1990, os países emergentes, em especial os da América Latina, abriram os mercados para a atuação de bancos estrangeiros colocando-os como peça fundamental para ganho de eficiência, estabilidade do sistema bancário e aumento de crédito. Assim, fomentaram oportunidades para os bancos estrangeiros que penetraram através de aquisição de bancos privados e públicos. Em ambos os casos, as instituições entrantes foram beneficiadas ao comprar uma marca, ativos, conquistar clientes, redes de agências e postos de atendimento. Com este comportamento, os bancos estrangeiros incorporaram a característica de deslocamento das atividades bancárias e a aquisição de instituições locais típicas da nova face da internacionalização bancária nos anos 1990. O resultado para os países da América Latina foi a desnacionalização quase completa dos sistemas bancários, que ocorreu de forma mais aguda no Chile e na Argentina.

Entretanto, como observam Carvalho et al. (2002) e Rocha (2002), tomando como base o Brasil, os bancos estrangeiros adaptaram-se à dinâmica nacional passando a atuar de forma semelhante aos bancos nacionais, mantendo o foco nas atividades de curto prazo, financiamento da dívida pública e cobrança de altos juros e tarifas. Uma das explicações é que o negócio bancário é, acima de tudo, um negócio. Portanto, os bancos buscam lucro e, se podem obter grandes ganhos agindo como os bancos nacionais, estariam pouco motivados a provocar mudanças concorrenciais.

\section{EVIDÊNCIAS DA FORMAÇÃO DAS MULTINACIONAIS BANCÁRIAS BRASILEIRAS}

Nesta parte vamos discutir se procede o objetivo motivador do trabalho sobre a formação de multinacionais bancárias brasileiras. Assim, em um primeiro momento, a tarefa é selecionar as maiores instituições e ver qual a relação delas com a internacionalização e, em seguida, explorar a visão sobre o futuro das estratégias de expansão internacional.

\subsection{QUADRO ATUAL}

Este item pretende mostrar o grau de envolvimento dos bancos nacionais mais relevantes com as atividades internacionais. Primeiramente, é necessário identificar o tipo de instituição financeira a ser analisada. Para nosso objetivo foram selecionados os bancos que possuem informações detalhadas divulgadas pelo Banco Central do Brasil (BACEN) como forma de garantir a solidez do sistema bancário nacional.

Segundo o BACEN (2012), existiam 132 bancos em funcionamento no Brasil em setembro de 2011. Desta relação, neste artigo, foram excluídos os bancos de desenvolvimento e fomento, por não se encaixarem no escopo do trabalho. Destes bancos adotamos a classificação pelos ativos totais como forma de mensurar a influência das instituições na economia e a sua capacidade de se transformarem em multinacionais bancárias, devido à indicação da influência na indústria bancária (Tabela 2). Com base nesses dados identificamos dois aspectos. O primeiro é a elevada concentração em poucos bancos, já que os cinco maiores concentram $75 \%$ dos ativos bancários existentes no Brasil, indicando uma forte oligopolização do setor. O segundo é que entre os cinco maiores há apenas um estrangeiro e, mesmo assim, com menos da metade da participação do Banco do Brasil.

\begin{tabular}{|c|c|c|}
\hline & Ativos (em R\$ mil) & Participação (em\%) \\
\hline Cinco Maiores & 3.284.321.498 & 75,55 \\
\hline 10 Maiores & 3.774 .893 .767 & 86,83 \\
\hline 20 Maiores & 4.021 .502 .176 & 92,50 \\
\hline Total & 4.347.484.630 & 100,00 \\
\hline
\end{tabular}

Fonte: BACEN (2012)

Dos cinco maiores bancos destacamos que quatro são nacionais: Banco do Brasil, Caixa Econômica Federal, Bradesco e Itaú/Unibanco. Os dois primeiros são públicos ou com participação estatal (Tabela 3). O único estrangeiro que figura no grupo é o 
espanhol Santander, que alçou essa posição após grandes aquisições, como do Banespa (1997) e Banco Real (2009), mas possui cerca da metade dos ativos dos líderes do setor, que são: Banco do Brasil, Itaú/Unibanco e Bradesco. Como característica em comum os cinco atuam como conglomerados financeiros com operações nas mais diferentes áreas como cartões de crédito, seguros, financiamento, atuação no mercado financeiro, entre outros.

Tabela 3 - Divisão dos ativos entre os cinco maiores bancos no Brasil (setembro de 2011)

\begin{tabular}{lcc}
\hline & Ativos (em R\$ mil) & Participação (em \%) \\
\hline Banco do Brasil & $907.743 .033,00$ & 27,64 \\
Itaú/Unibanco & $810.464 .986,00$ & 24,68 \\
Bradesco & $636.399 .735,00$ & 19,38 \\
Caixa Econômica Federal & $507.306 .734,00$ & 15,45 \\
Santander & $422.407 .010,00$ & 12,86 \\
Total & $\mathbf{3 . 2 8 4 . 3 2 1 . 4 9 8 , 0 0}$ & $\mathbf{1 0 0 , 0 0}$ \\
\hline
\end{tabular}

Fonte: BACEN (2012).

A partir dos dados passamos a dar atenção aos bancos nacionais e a investigar o quadro de atuação internacional dessas instituições. Desta forma, vamos analisar como encaram as atividades no exterior e como podem contribuir para o embrião do que pode vir a se tornar uma multinacional bancária.

\subsubsection{BANCO DO BRASIL}

De acordo com Dalla Costa e Souza Santos (2011), o Banco do Brasil possui uma longa história de internacionalização devido à forte ligação com as políticas públicas de comércio exterior. Assim, nos anos 1960/1970 o Banco caminhava para ser a primeira multinacional bancária brasileira ao atuar nos mercados europeus, norte-americano, latino-americano, africano, australiano e asiático, presente nas principais praças financeiras e operações de investimento.

Entretanto, a crise dos anos 1980 seguida da reestruturação interna na década seguinte levaram ao enxugamento da estrutura internacional e à paralisação dos planos de expansão. Entre as medidas estavam a redução de funcionários, escritórios de representação, agências e operações financeiras. O foco das atividades passou a ser o apoio a empresas e clientes brasileiros no exterior em conjunto com a esfera financeira. Apesar de haver atuação internacional, continua sendo difícil encontrar dados claros a respeito do grau de envolvimento internacional da instituição, como ativos, passivos e agências.

Tabela 4 - Expansão internacional do Banco do Brasil (1960-1980)

\begin{tabular}{|c|c|}
\hline Ano & Fato \\
\hline \multirow{3}{*}{1967} & Agências na Bolívia, em Santa Cruz de la Sierra \\
\hline & Negociações para instalação de agências no Perú \\
\hline & $\begin{array}{l}\text { Filiais e escritórios na Cidade do México (México), Bogotá (Colômbia), Caracas (Venezuela) e Quito } \\
\text { (Equador) }\end{array}$ \\
\hline 1969 & $\begin{array}{l}\text { Autorização para abertura de filial em Nova Iorque tendo como justificativa o intercâmbio comercial e } \\
\text { financeiro entre Brasil e Estados Unidos }\end{array}$ \\
\hline \multirow{2}{*}{1970} & $\begin{array}{l}\text { Inauguração da agência em Hamburgo (Alemanha) e início do funcionamento de escritórios em Paris } \\
\text { (França), Londres (Grã-Bretanha) e Tóquio (Japão) }\end{array}$ \\
\hline & $\begin{array}{l}\text { Instalação em Londres, maior mercado financeiro mundial, passando a participar do mercado de } \\
\text { euromoedas e "reciclagem de petrodólares" }\end{array}$ \\
\hline & Existência de 975 agências em território nacional e 14 no exterior \\
\hline 1971 & $\begin{array}{l}\text { Criação da European Brazilian Bank Ltd. (Eurobraz), uma empresa de investimentos. Posteriormente, } \\
\text { associados a Cia. Arabe et Internationale d'Investissement de Luxemburgo, o Banque Arabe et } \\
\text { Internationale d' Investissement em Paris, e o Brazilian American Merchant Bank de capital exclusivo } \\
\text { do BB em Grand Cayman }\end{array}$ \\
\hline 1977 & $\begin{array}{l}\text { Escritórios de representação em Sydney (Austrália) e Lagos (Nigéria), além da participação em } \\
\text { empreendimentos diversos e representado por } 36 \text { agências }\end{array}$ \\
\hline 1980 & $\begin{array}{l}\text { Rede externa com } 61 \text { unidades, três subsidiárias, presente em Viena (Áustria) e Macau, além de estudos } \\
\text { para a instalação de dependências em Varsóvia (Polônia) }\end{array}$ \\
\hline 1982 & $\begin{array}{l}\text { Criação da BB-Leasing Company Ltd. sediada em Grand Cayman visando o financiamento do } \\
\text { arrendamento das plataformas de prospecção de petróleo para a Petrobras; Na África Mediterrânea, } \\
\text { criação de novas agências no Cairo, Casablanca e Túnis; ao sul do Saara, em Dakar e Libreville; Em } \\
\text { Paris, inauguração da BB-Tours Voyages et Tourisme visando a ampliação do turismo para o Brasil. }\end{array}$ \\
\hline
\end{tabular}

Fonte: Elaboração própria com base em dados do Banco do Brasil (2010).

\subsubsection{ITAÚ/UNIBANCO}

O Itaú/Unibanco encara a internacionalização de uma forma integrada no plano de negócios que, não apenas acompanha os clientes, mas busca colocar a instituição como um conglomerado internacional que inicia a competição com bancos locais. Como destaque desta política aparece um total de US\$ 13 bilhões em patrimônio líquido consolidado em setembro de 2011 (Tabela 5).

O patrimônio líquido no exterior representava cerca de um terço do total de R $\$ 69$ bilhões em setembro de 2011. Ao serem transformados em Reais pela taxa de câmbio médio daquele período, que era de R $\$ 1,75$, os US\$ 13 bilhões, representavam cerca de $\mathrm{R} \$ 22$ bilhões. 
Tabela 5 - Distribuição de ativos e patrimônio líquido do Itaú/Unibanco (setembro de 2011)

\begin{tabular}{lrc}
\hline & Ativos & $\begin{array}{c}\text { Patrimônio Líquido } \\
\text { (em US\$ mil) }\end{array}$ \\
\hline Agências no Exterior & 67.376 & 6.622 \\
Consolidado Itaú Argentina & 1.715 & 163 \\
Itaú Europa Consolidado & 7.995 & 855 \\
Consolidado Cayman & 9.019 & 3.830 \\
Consolidado Chile & 7.979 & 1.014 \\
Consolidado Uruguai & 2.499 & 195 \\
Banco Itaú Paraguay & 1.960 & 233 \\
Demais Empresas no Exterior & 1.112 & 1.193 \\
Consolidado no Exterior & $\mathbf{9 0 . 9 2 4}$ & $\mathbf{1 3 . 8 5 2}$ \\
\hline
\end{tabular}

Fonte: Itaú/Unibanco (2012).

\subsubsection{BRADESCO}

O Bradesco possui agências e subsidiárias no estrangeiro que, segundo o próprio banco têm a função de dar suporte aos clientes brasileiros no exterior por meio da obtenção de recursos para repasses a operações de comércio exterior (Tabela 6).

Tabela 6 - Distribuição de ativos e patrimônio líquido do Bradesco (setembro de 2011)

\begin{tabular}{lrc}
\hline & Ativos & $\begin{array}{c}\text { Patrimônio Líquido } \\
\text { (em US\$ mil) }\end{array}$ \\
\hline Bradesco Nova Iorque & 17.138 & 269 \\
Bradesco Grand Cayman & 28.777 & 3.528 \\
Bradesco Grand Cayman 2 & 6.057 & 5.842 \\
Bradesco Nassau & 0 & 0 \\
Cidade Capital Markets Ltd. - Grand Cayman & 38 & 38 \\
Bradesco Services Co., Ltd. - Tóquio & 1 & 1 \\
Banco Bradesco Argentina S.A. & 50 & 27 \\
Banco Bradesco Europa S.A. & 1.716 & 339 \\
Total & 53.777 & $\mathbf{1 0 . 0 4 4}$ \\
\hline
\end{tabular}

Fonte: Bradesco (2012)

O patrimônio líquido no exterior representava cerca de um terço do total de R \$ 53 bilhões em setembro de 2011 que, ao serem transformados em reais pela taxa de câmbio médio do período, que era de R $\$ 1,75$, os US\$ 10 bilhões representavam cerca de R\$ 17 bilhões.

\subsubsection{CAIXA ECONÔMICA FEDERAL}

Ao pesquisar o site oficial do banco ${ }^{2}$, observa-se que a internacionalização é baseada na criação de redes no Japão, Estados Unidos e Europa, que permitam que os brasileiros localizados no exterior tenham facilidade em remeter recursos para o país. No caso desta instituição, sua atuação constitui-se em um nicho muito específico e não busca competir localmente ou aprofundar as relações na esfera financeira.

\subsection{IDENTIFICAÇ̃̃O DAS ESTRATÉGIAS E MOVIMENTOS}

Neste item mapeamos os movimentos dos grandes bancos em relação à internacionalização enfatizando ações e planos que resultam no deslocamento das atividades bancárias por constituírem uma evidência de mudança estrutural no pensamento das instituições líderes. Os protagonistas selecionados são Itaú/Unibanco, Bradesco e Banco do Brasil.

No dia 3 de novembro de 2008, Itaú e Unibanco assinaram um contrato de associação para unificação das operações financeiras dos dois bancos, oficializando o processo de fusão que criou um dos maiores conglomerados do hemisfério sul e do mundo (Itaú/Unibanco, 2010). No calor do negócio, o presidente-executivo do novo grupo, Roberto Setúbal, declarou que "nós [o Brasil] precisamos de um banco internacional. Esse banco, com uma base de capitalização forte, terá capacidade de financiar as empresas que estão se internacionalizando" (Salles, 2008, p. 1).

A fala de Setúbal deixa evidente que a fusão estava relacionada com a necessidade de criar um grupo forte e capaz de competir internacionalmente. Logo depois, na mesma entrevista Setúbal declara que "a América Latina é um lugar natural para um banco brasileiro se internacionalizar. Há outros países [latino-americanos] que são atraentes e onde não estamos como México e Colômbia" (Salles, 2008, p. 1).

Em seguida, surgiram os rumores de negociações para a aquisição de instituições de outros países em decorrência de em uma estratégia agressiva de expansão internacional planejada para ganhar força quando da integração entre os bancos. No começo de 2010, palpitavam rumores da compra de ações dos bancos europeus RBS e Lloyds, defendida por um dos conselheiros do Grupo, Pedro Malan, em paralelo estudando a participação em instituições financeiras de outros países, incluindo os EUA. Entre os negócios efetivados estão a aquisição do banco argentino Del Buen Ayre em 1998 ,

2 Ver http://www.caixa.gov.br. 
parcerias com BPI (Portugal), Unicredito (Itália) e La Caixa (Espanha) em 2005, aquisição do Bank Boston da América Latina em 2006, que permitiu ao banco atuar no varejo do Uruguai e Chile (Seeb, 2010).

A outra principal instituição privada nacional, o Bradesco, oficialmente não enfatiza a internacionalização como parte da visão de negócios, e as unidades no exterior têm como objetivo atender aos clientes brasileiros (físicos e jurídicos), em relação às necessidades no mercado externo, como a obtenção de recursos, especialmente voltados para o comércio internacional. Entretanto, no começo de 2010 iniciou a negociação para a aquisição do Ibi no México, justificada pelo diretor do Bradesco Cartões, Marcelo Noronha, como uma mera compra de oportunidade. Contudo, a Ibi é a marca de cartões oficiais da loja de departamentos C\&A, estendendo uma parceria consolidada no Brasil há mais de 20 anos. A carteira do Ibi México envolve um milhão de cartões, carteira de crédito equivalente a R $\$ 180$ milhões distribuídos em 55 lojas da C\&A (Laguna, 2010). Além disso, em 2010 firmou entendimentos para a parceria com o Banco do Brasil e o português Banco Espírito Santo (BES) para conquistar o mercado não-bancarizado africano (Silva Junior, 2011).

No caso do Banco do Brasil, a instituição apresenta como fator propulsor o incentivo do Estado brasileiro, que é o acionista majoritário e influencia nas suas estratégias, o que fica evidenciado nas declarações do então Presidente Luiz Inácio Lula da Silva em 2009 "o BB precisa virar o banco mais importante da geografia política do nosso continente" (Duarte, 2009, p. 1). De certa forma, o Presidente estava colocando a internacionalização do Banco do Brasil como uma ação estratégica de sua política externa.

Em dezembro de 2009, o Banco do Brasil conseguiu autorização para negociar ações na bolsa de Nova Iorque, em parte utilizada para levantar recursos a fim de impulsionar expansão e aquisição de instituições no exterior. Em relação às aquisições, o destaque foi a compra do argentino Banco da Patagônia, por representar um passo real e marcante em nome da internacionalização. Esta operação envolveu a quantia de US\$ 480 milhões para ficar com o controle acionário. Assim, o Banco do Brasil passou a deter $51 \%$ do capital votante, exatas 366.825 .016 ações, a um preço de US\$1,3076 por ação, totalizando US\$ 479,66 milhões. Segundo o comunicado, o Patagônia possuía, no fim de 2009, cerca de 2,57 bilhões de dólares em ativos, carteira com mais de 775 mil clientes e 2.660 funcionários (Barbosa, 2010), além de parcerias com o português BES e Bradesco para atuar na África.

Após a primeira compra efetiva de um concorrente internacional, começaram a aparecer rumores na imprensa sobre a negociação do Banco do Brasil para aquisição de outras instituições. A ideia é seguir buscando oportunidades, inclusive nos Estados Unidos, em busca de iniciar uma grande onda de aquisições. Um destaque especial é o plano de adquirir um banco norte-americano para se fixar naquele mercado (Seeb,
2010). Dando prosseguimento a esta política, em 2011 o Banco do Brasil comprou o EuroBank, de pequeno porte, com apenas três agências, no Estado da Flórida. De acordo com seus executivos, nos três anos seguintes o BB investiria US\$ 25 milhões nos EUA. Segundo declarações do vice-presidente de negócios internacionais, Alan Simões Toledo, a estratégia de internacionalização foi desenhada para acompanhar três movimentos: a) a expansão para outros países de empresas brasileiras; b) a presença de brasileiros em países estrangeiros; c) o aumento de fluxos de comércio do Brasil com o resto do mundo (Modé e Silveira Junior, 2011).

\section{FATORES PROPULSORES E INIBIDORES}

Após identificar a existência do fato na seção anterior é o momento de verificar os motivos propulsores e inibidores da formação de multinacionais bancárias brasileiras. Em que pese uma mudança na dinâmica dos últimos anos em que o otimismo e a motivação para a internacionalização passaram a dar lugar à cautela e ao temor, devido aos efeitos desestabilizadores da crise financeira internacional iniciada em 2008 e sem uma resolução previsível.

\subsection{PROPULSORES}

Os motivos propulsores identificados foram os seguintes: i) a solidez institucional da formação dos bancos brasileiros; ii) a abertura/reestruturação/ o choque de competição na década de 1990 forçou as instituições a repensarem seu negócio; e iii) o momento favorável da economia brasileira e a força de seu mercado interno.

\subsubsection{SOLIDEZ INSTITUCIONA}

Para compreender a solidez institucional da indústria bancária brasileira é necessário, primeiramente, abordar o ambiente e, em seguida, lançar o olhar para os grandes bancos nacionais. Fazendo isso é possível identificar que o país é portador de instituições bancárias de uma longa tradição, fortalecidas ao longo do tempo pelo processo de concentração bancária.

A formação dos principais bancos nacionais deu-se na década de 1930, quando os sistemas financeiros e de crédito começaram a ser importantes para a economia brasileira devido aos processos de industrialização e desenvolvimento. Porém, como mos- 
tra Studart (1995), o sistema financeiro era desorganizado, e a indústria bancária era dominada por pequenas instituições frágeis, aproveitando-se do ambiente de bonança, alta inflação e oportunidades de especulação. O resultado foi que entre 1945 e 1964 o número de bancos caiu de 509 para 328, devido, na visão de Macarini (2007), à fragilidade dos bancos e à formatação do sistema financeiro brasileiro.

Como resultado havia uma estrutura financeira e bancária incapaz de dar suporte ao aprofundamento das políticas desenvolvimentistas enfrentadas pelo Governo Militar por meio da Reforma Campos-Bulhões a partir de 1964. Inspirada no modelo norte-americano do pós-1929, tal reforma pregava a criação de bancos especializados, sobretudo de investimentos, a fim de criar linhas de financiamento privado de longo prazo. Entretanto, a ideia inicial fracassou, especialmente em relação aos bancos de investimento, por serem incompatíveis com o ambiente de instabilidade, inflação e especulação (Studart, 1995). Ao mesmo tempo, Macarini (2007) ressalta que dentro do regime militar passou a se fortalecer a ideia da criação de grandes instituições que dariam maior estabilidade e redução de custos, refletindo em um menor spread e maior abundância de crédito. Tal fenômeno levou à onda de fusões e aquisições vista como positiva para a criação de grandes conglomerados financeiros que apoiassem o setor produtivo dentro da lógica de "construção do poder nacional".

Dentre os bancos privados vencedores neste processo destacamos os RUBI (Banco Real, Unibanco, Bradesco e Itaú), um apelido dado por Costa (2002) quando estudou a trajetória das quatro instituições:

- O Banco Real teve origem em Minas Gerais, em 1920, como um pequeno banco formado por fazendeiros mineiros, denominado "Banco da Lavoura". Paulatinamente, foi aumentando a sua gama de produtos e rede de agências a ponto de, em 1950, ser considerado o maior banco brasileiro em volume de depósitos. Porém, em 1971, ocorreu a cisão devido aos conflitos entre os dois irmãos, Aloyzio e Gilberto, filhos do principal fundador, Clemente de Faria, dando origem ao Banco Bandeirantes e Real.

- Unibanco: também tem origem em Minas Gerais, na década de 1920, como um pequeno posto bancário que, em 1931, passou a se chamar Banco Moreira Salles. Após um rápido crescimento se fundiu com o Banco Agrimer e Agrícola Mercantil (em 1967), dando lugar a União de Bancos Brasileiros S.A., na década de 1970 incorporando o Banco Predial, assumindo em 1975 o nome Unibanco.

- Bradesco: é um banco paulista originado na Casa Bancária Almeida, em Marília, fundada por um grupo de amigos que visava transformá-la em banco. Para isso, foi chamado o experiente Amador Aguiar, nos anos 1940. A partir de 1946, quando a sua sede foi transferida para a capital paulista, a instituição imprimiu um ritmo alucinante de expansão com aquisições, ampliação da sua rede de agências, captação de depósitos e prestação de serviços (cobranças, por exemplo) transformando-se no maior banco do país, nos anos 1970.

- Itaú: nasceu em 1944 no estado de São Paulo, tendo como origem de seu capital a Cia. de Cimento Itaú, fundada, principalmente, pela família Setúbal. O grande impulso deu-se com a fusão com o Banco Federal de Crédito em 1964, passando a ser denominado Banco Federal Itaú, mais tarde, apenas Itaú, seguida de aquisições como o Banco Sul Americano do Brasil, Banco América, Banco Português e herdou o Banco União Comercial, que estava em situação pré-falimentar e que era um dos maiores bancos brasileiros.

Na década de 1980, as instituições do RUBI firmavam-se como bancos múltiplos que operavam como conglomerados financeiros consolidando o projeto de expansão (Costa, 2002), oferecendo produtos, como seguros e administração de consórcios, sendo beneficiados pelo ambiente de alta inflação que lhes permitia ganhos fáceis na especulação e dívidas do governo. Por exemplo, o Bradesco consolidou a sua posição de maior banco brasileiro e da América Latina com mais de 1,4 mil agências e dois milhões de acionistas. Ou, no caso do Itaú, o banco passou a atuar na área química e eletrônica com a Itautec e Philco. Dos RUBI, o único que sucumbiu à abertura do mercado bancário foi o Banco Real, adquirido pelo holandês ABN AMRO em 1998, desaparecendo a marca em 2008, quando as operações foram adquiridas pelo espanhol Santander.

Dos bancos estatais que atuavam como bancos comerciais, o destaque é para o Banco do Brasil e a Caixa Econômica Federal. Ambos foram fundados no século XIX, mas o Banco do Brasil foi direcionado para a competição no mercado e, a Caixa, para apoio a políticas públicas como saneamento e habitação. Por isso, é normal destacar o Banco do Brasil como o mais capaz de competir com as instituições privadas e disputar mercado nacional e internacional. Adicionalmente, no período surgiram bancos estaduais que serviam como impulsionadores do desenvolvimento local com funções comerciais (por exemplo, o Banespa, em São Paulo e o Banestado, no Paraná), mas que em sua maioria foram privatizados nos anos 1990, tendo como principais compradores bancos estrangeiros e nacionais privados buscando consolidar e ampliar a participação no mercado nacional.

\subsubsection{ABERTURA/REESTRUTURAÇÃO/CHOQUE DE COMPETIÇÃO}

No Brasil, trabalhos como os de Corazza (2000), Carvalho et al (2002), Paula e Alves Jr. (2007) enfatizam duas mudanças estruturais no mercado bancário ao longo da década 
de 1990. Uma foi a abertura de mercado que permitiu a operação de instituições estrangeiras e a outra, o controle da inflação pós-1994, que retirou dos bancos a maior fonte de receita que encobria ingerências e fragilidades. Por isso, Corazza (2000) observa que o resultado foi uma crise bancária até mesmo em bancos de grande porte, como Econômico, Nacional e Bamerindus, que trouxe à tona o plano de reestruturação do setor.

O processo de reestruturação ganhou força em 1994/1995 provocando a concentração, a atração de instituições estrangeiras e a redução da participação dos bancos públicos. Segundo Reis e Valadares (2004), envolveu o Programa de Estímulo à Reestruturação e ao Fortalecimento do Sistema Financeiro Nacional (PROER), cujo objetivo era dar solidez aos bancos e evitar que as dificuldades de algumas instituições se alastrassem pelos demais e gerassem crises sistêmicas, especialmente, recorrendo à penalização da má gestão. Ao mesmo tempo foi criado o programa de Redução da Participação do Setor Público Estadual na Atividade Bancária (PROES), que incentivava a privatização dos bancos estaduais reduzindo o número de 35 para 12 até o ano de 2000. Adicionalmente, Carvalho et al. (2002) enfatizam que o governo Fernando Henrique via com bons olhos a entrada de instituições estrangeiras, baseado na visão convencional sobre os benefícios, mesmo destacando que uma das portas de entrada dessas instituições era a aquisição de bancos públicos em processo de privatização e bancos nacionais em dificuldades.

Os "RUBI" saíram fortalecidos do processo e com oportunidades de ampliar sua participação no mercado através de aquisição de bancos públicos e da absorção de instituições em dificuldade. Mesmo ganhando competidores internacionais de peso como HSBC e Santander, conseguiram se modernizar e ganhar eficiência. A única baixa foi a do Banco Real adquirido pelo ABN AMRO, em 1998.

O Banco do Brasil (2010) passou por uma profunda reestruturação durante o primeiro governo Fernando Henrique (1994-1998) na busca de voltar a ser competitivo e sólido, ganhando para isso tons mais comerciais com o foco em resultados. Assim, mesmo como uma instituição pública, admitiu acionistas privados e teve uma visão comercial do negócio em busca de competir com os demais bancos comerciais privados nacionais e internacionais. Trata-se de uma característica não tão presente em outro grande banco federal, a Caixa, que apesar de atuar no varejo tem tanto sua estrutura quanto as demais atividades voltadas para atividades públicas.

Finalmente, o resultado do processo de reestruturação do setor bancário brasileiro foi a formação de três grandes instituições nacionais potencialmente capazes de alçarem voos internacionais: Itaú/Unibanco, Bradesco e Banco do Brasil (Tabela 7). Os três bancos possuem uma forte base no mercado interno e uma estrutura institucional que garante a solidez da indústria bancária e lhes permite traçar uma estratégia de ocupação do mercado externo.
Tabela 7 - Principais números dos cinco maiores bancos presentes no Brasil (setembro de 2011)

\begin{tabular}{lcccccc}
\hline & $\begin{array}{c}\text { Ativos } \\
\text { Totais }\end{array}$ & $\begin{array}{c}\text { Patrimônio } \\
\text { Líquido }\end{array}$ & $\begin{array}{c}\text { Lucro } \\
\text { Liquido }\end{array}$ & $\begin{array}{c}\mathbf{N}^{\circ} \text { de } \\
\text { Funcionários }\end{array}$ & $\begin{array}{c}\mathbf{N}^{\circ} \mathbf{d e} \\
\text { Agências }\end{array}$ & $\begin{array}{c}\text { Índice de } \\
\text { Basileia }\end{array}$ \\
\hline Banco do Brasil & 907.743 .033 & 54.645 .315 & 2.917 .897 & 131.640 & 5.156 & 14,5 \\
Itaú/Unibanco & 810.464 .986 & 69.359 .236 & 3.820 .016 & 122.653 & 3.796 & 15,1 \\
Bradesco & 636.399 .735 & 53.923 .720 & 5.564 .701 & 94.516 & 3.953 & 15 \\
Caixa Econômica Federal & 507.306 .734 & 18.027 .962 & 1.291 .175 & 109.163 & 2.252 & 13,4 \\
Santander & 422.407 .010 & 65.999 .809 & 880.654 & 52.162 & 2.449 & 24,2 \\
\hline
\end{tabular}

Nota: valores monetários em $\mathrm{R} \$$ mil e lucro liquido do $3^{\circ}$ trimestre de 2011

Fonte: BACEN (2012).

Dentre os cinco maiores bancos atuantes no Brasil destacam-se os nacionais (Itaú, Banco do Brasil, Bradesco e Caixa Econômica Federal), ao passo que os três primeiros apresentam vantagens quantitativas em relação aos demais. Dessa forma, as grandes instituições internacionais, mesmo que inseridas há mais de uma década no país, não conseguiram desbancá-las. O Índice de Basileia dos principais bancos brasileiros gira em torno de 15, o que indica elevada resistência e acima do mínimo estabelecido pela legislação brasileira (que é 11), representando uma potencial vantagem competitiva e poder para atuar fora do país.

\subsubsection{MOMENTO ECONÔMICO FAVORÁVEL}

Durante o governo Lula os bancos e as instituições financeiras beneficiaram-se pela força do mercado interno provocada pelo crescimento econômico com estabilidade que alavancou o crédito, atraiu novos clientes e possibilitou a venda de uma ampla gama de serviços, como seguros e cartões de crédito. Dessa forma, os ativos de bancos brasileiros ficaram valorizados pela perspectiva de crescimento e valorização do Real, a ponto de as instituições estrangeiras preferirem fornecer recursos as instituições nacionais e evitar uma competição direta.

Entretanto, o crescimento do mercado de crédito, produtos financeiros e outros serviços atraiu uma nova onda de entrada de bancos estrangeiros no Brasil que preferem gravitar na área de supervisão e financeirização. Assim, como observa Costa (2010), evitavam entrar em confronto com os bancos estabelecidos devido à elevada concorrência e ao custo de entrar no mercado à medida que os ativos nacionais se valorizaram. Não que o crescimento das oportunidades de ganhos no setor financeiro seja monopólio dos grandes bancos, mas são esses os que apresentam um crescimento substancial na lucratividade batendo recordes sucessivos (Tabela 7). 


\subsection{INIBIDORES}

Os fatores inibidores da internacionalização das potenciais multinacionais bancárias nacionais ganharam força com a crise financeira de 2008, iniciada nos Estados Unidos, alastrada pela Europa e outras regiões do mundo. Inicialmente, aparentando ser um fator positivo, na medida em que deprimia os preços dos ativos de bancos em países em crise, a crise logo mostrou-se um fator de instabilidade e incerteza a respeito da viabilidade e do risco da entrada em novos mercados e a aquisição de instituições estrangeiras que podem estar em dificuldades.

Na origem, Hale (2011) observa que a crise teve início no mercado bancário e interbancário, rapidamente contaminando outros mercados de capitais. Ao mesmo tempo, as instituições financeiras foram afetadas negativamente comprometendo a confiança, o valor de mercado e o fluxo de crédito. Em seguida, o que se viu foi a quebra de grandes bancos aparentemente sólidos, como o Lehman Brothers, em 2008, acompanhados de outros que entraram em dificuldades, como JP Morgan, City Group, Goldman Sachs e Bank of America, todos batendo recordes negativos. Mesmo em 2011, quando a crise parecia superada, cerca de 800 instituições passavam por dificuldades e 74 estabelecimentos foram fechados nos primeiros nove meses (Isto É Dinheiro, 2011). Ainda é uma situação indefinida, porque existem inter-relações financeiras nebulosas entre os cerca de cinco mil estabelecimentos norte-americanos que podem comprometer instituições aparentemente saudáveis.

Neste primeiro momento criou-se o temor de entrar no mercado norte-americano adquirindo instituições devido à possibilidade de um banco com ativos tóxicos, não saber os rumos da regulação e, nem mesmo, a demanda por serviços financeiros nos próximos anos. Inicialmente, em 2007/2008, a entrada no mercado bancário dos EUA parecia tentadora, mas o aprofundamento da crise colocou os riscos potenciais em evidência, ultrapassando possíveis benefícios.

$\mathrm{Na}$ Europa, a crise chegou pelos países periféricos, inicialmente, pela Grécia, seguida de Portugal, Irlanda, Hungria e, em seguida, Espanha e Itália. Não se criava um novo problema, mas se trazia à tona o problema estrutural da integração europeia e da adoção de uma moeda única sem o contraponto da unificação fiscal e política reais de redução das desigualdades. Este fenômeno gerou críticas como as de Joseph E. Stiglitz (2014) e Paul Krugman (2011) de que o verdadeiro problema está travestido no discurso da irresponsabilidade fiscal, tendo como solução políticas recessivas e de combate ao déficit.

$\mathrm{Na}$ indústria bancária, o projeto de unificação bancária da União Europeia permitiu que as instituições nacionais criassem mercados interbancários abrangendo diversos países da região, direta ou indiretamente, envolvidos com as dívidas soberanas dos países da Eurozona e sob o risco de default dos membros em dificuldades. Tal situação criou um potencial risco sistêmico que desencorajou aquisições e participações acionárias em bancos da região, além de prever o comportamento do mercado europeu e a demanda por serviços bancários.

Outra região que desperta o interesse dos bancos brasileiros é a África, que tem como atrativo não possuir bancos tradicionais, um grande mercado de não-bancarizados e elevado crescimento baseado na demanda de commodities. Se, por um lado, é necessário construir a rede bancária do zero, por outro, a possibilidade de ganhos também é elevada girando com lucros em torno de $45 \%$. Porém, a crise criou uma situação de incerteza a respeito de como a economia africana vai ser comportar. Este fato evidencia-se nas declarações do presidente do Banco do Brasil, Aldemir Bendine, de que o "cenário mais incerto tem gerado atraso nas negociações em curso" (Silva Junior, 2011, p. 1). O executivo complementa que "a entrada só não ocorreu ainda por questões negociais e pela falta de uma oportunidade melhor" (ibidem).

O ambiente de instabilidade e incerteza mundial, especialmente nas regiões foco do processo de internacionalização dos grandes bancos brasileiros, incentivou o congelamento das atividades e o retorno para o mercado interno, relativamente protegido. Outro caminho seria colocar a estratégia de expansão sobre os países da América Latina que, por serem mais próximos do Brasil e relativamente menos instáveis, poderiam proporcionar oportunidades mais seguras.

\section{CONSIDERAÇÕES FINAIS}

A motivação do trabalho estava em investigar a natureza da internacionalização bancária e a formação de multinacionais brasileiras capazes de serem competitivas no cenário internacional e agirem como conglomerados financeiros. Ficou evidenciado que um movimento pró-ativo poderá trazer potenciais mudanças estruturais no mercado interno.

O primeiro passo foi apresentar o panorama sobre internacionalização bancária destacando dois pontos: um, a introdução do deslocamento das atividades bancárias como uma nova forma de internacionalização incorporada pelos europeus nos anos 1990; e outro, a liderança de grandes bancos no movimento de internacionalização passando a competir nas praças estrangeiras batendo de frente com as instituições locais.

Em seguida, identificamos a existência do objeto do trabalho. A resposta foi afirmativa. Os bancos nacionais começam a intensificar o envolvimento com operações no exterior. Os líderes do processo são: Banco do Brasil, Itaú/Unibanco e Bradesco, que possuem planos de expansão internacional e já adquiriram instituições no exte- 
rior. Merece destaque a fusão entre Itaú e Unibanco, justificada como forma de criar um conglomerado capaz de competir com os congêneres estrangeiros, e o fato de que cerca de um terço do patrimônio líquido do Itaú/Unibanco e Bradesco encontram-se no exterior.

Na última seção, o foco deslocou-se para explorar os motivos propulsores e inibidores. Como propulsores destacamos três aspectos. O primeiro é a solidez institucional que, de uma forma ou de outra, permitiu a criação de instituições fortes ao longo do tempo e capazes de suportar a competição com conglomerados internacionais no mercado interno. Neste caso o Brasil diferencia-se de outros países, como Chile e Argentina, que tiveram seus bancos nacionais exterminados com a abertura dos anos 1990. O segundo foi a abertura/reestruturação/choque de competição na década de 1990 que forçou as instituições a se modernizarem e readaptarem à lógica de mercado. Mesmo sendo uma mudança dolorosa e crítica, fortaleceu a indústria bancária nacional. Por fim, momento favorável da economia brasileira e forte mercado interno ao longo da década de 2000, criando uma base capaz de suportar voos internacionais.

Por outro lado, os inibidores estão baseados no risco da instabilidade financeira e econômica na aquisição e nas operações no exterior, principalmente nos mercados mais visados que são Estados Unidos, Europa e África. Tal fenômeno foi acentuado com a crise financeira iniciada em 2008, que prossegue sem desdobramento previsível nos próximos anos criando um clima de incerteza para a formulação de estratégias. Este último fato pode levar a uma tendência de concentração da expansão sobre a América Latina por estar mais próxima do Brasil e menos sujeita às instabilidades globais.

No decorrer da pesquisa foi possível identificar tendências à criação de multinacionais bancárias brasileiras de atuação global na linha do espanhol Santander e do britânico HSBC. Entretanto, a instabilidade e o clima de incerteza emergidos com a crise financeira de 2008 podem ter amenizado os planos e colocado a cautela à frente do otimismo, incentivando os bancos a se voltarem para o mercado interno como um porto seguro para manter a solidez e, eventualmente, nos próximos anos adotar uma estratégia agressiva de expansão internacional.

\section{REFERÊNCIAS}

ABDELAL, R.; RUGGIE, J. The principles of embedded liberalism: social legitimacy and global capitalism. In: MOSS, D.; CISTERNINO, J. (Orgs.) New perspective on regulation. Cambridge: The Tobin Project, p. 151-162.

ALIBER, R. Z. International banking: a survey. Journal of Money, Credit and Banking, v. 16, n. 4 , p. 661-678, 1984.
BANCO CENTRAL DO BRASIL (BACEN). Estatísticas sobre o SFN. Brasilia: BACEN, 2012. Disponível em: <http://www.bcb.gov.br/?ESTATSFN>. Acesso em: 12 jan. 2012.

BANCO DO BRASIL. Banco do Brasil 200 anos de história: 1964 - 2008. Belo Horizonte: Del Rey, Fazenda Comunicação \& Marketing, 2010.

BARBOSA, R. BB Compra banco argentino patagônia por US $\$ 480$ milhões. Revista Exame, São Paulo, 21/04/2014. Disponível em: <http://portalexame.abril.com.br/negocios/noticias/ banco-brasil-compra-argentino-banco-patagonia-r-480-milhoes-551747.html>. Acesso em: 25 abr. 2010.

BERGER, A. N.; DEMSETZ, R. S. STRAHAN, P. E. The consolidation of the financial services industry: causes, consequences, and implications for the future. Journal of Banking and Finance, v. 23, p. 135-194, 1999.

BERGER, A. N.; DEYOUNG, R.; GENAY, H.; UDELL, G. F. Globalization of financial Institutions: evidence from cross-border banking performance. Working Paper, Federal Reserve Bank of Chicago, WP-99-25, 2000.

BANK OF INTERNATIONAL SETTLEMENTS (BIS). Report on consolidation in the financial sector. [On-line] Group of Ten, BIS, jan. 2001. Disponível em: <http://www.bis.org/publ/ gten05.pdf>. Acesso em: 5 jan. 2011.

BRADESCO. Relação com investidores. Informações Corporativas. Canais de Distribuição. Bradesco no exterior. [On-line] Bradesco, 2014. Disponível em: <http://www.bradescori.com. br/abertura.html >. Acesso em: 12 jan. 2012.

CARVALHO, C. E.; STUDART, R.; ALVES JR, A. J. Desnacionalização do setor bancário e financiamento das empresas: a experiência brasileira recente. Textos para Discussão, IPEA, $\mathrm{n}$. $882,2002$.

CHICK, V.; DOW, S. C. "Competition and the future of the European banking financial system". In: COHEN, A.; HAGEMANN, H.; SMITHIN, J. (Orgs.) Money, financial institutions and macroeconomics. Boston: Kluwer, 1997, p. 253-270.

CORAZZA, G. Crise e reestruturação bancária no Brasil. Documento da Pesquisa. "Banco Central e Sistema Financeiro: crise e supervisão bancária no Brasil”. [On-line] UFRGS, 2000. Disponível em: <www.ufrgs.br/ppge/pcientifica/2000_08.pdf>. Acesso em: 03 mar. 2010.

CORAZZA, G.; OLIVEIRA, R. Os bancos nacionais face à internacionalização do sistema bancário brasileiro. Análise Econômica, Porto Alegre, v. 25, n. 47, 2007, p. 151-184.

COSTA, F. N. Desnacionalização: reserva e abertura do mercado aos bancos estrangeiros. [Online] Wordpress, 2010. Disponível em: <fernandonogueiracosta.files.wordpress.com/.../ aula-3-desnacionalizac3a7c3a3o-bancc3a1 ria.pdf>. Acesso em: 02 jan. 2011.

DAGES, B.; GOLDBERG, L.; KINNEY, D. Foreign and domestic bank participation in emerging markets: lessons from Mexico and Argentina. FRBNY Economic Policy Review, p. 17-36, set. 2000

DALLA COSTA, A.; SOUZA SANTOS, R. R. A internacionalização do Banco do Brasil em dois momentos distintos de sua história. Economia \& Teconologia, v. 26, p. 153-159, 2011.

DEMINGUC-KUNT, A.; HUIZINGA, H. Determinants of commercial bank interest margins and profitability: some international evidence. World Bank Discussion Paper, n. 1900, mar. 1998. 
DERMINE, J. European Banking: past, present and future. In: ECB Central Banking Conference, 2, Frankfurt, 24-25 out. 2002. Disponível em: <www.ecb.int/events/pdf/conferences/dermine_comp.pdf $>$. Acesso em: 30 jun. 2010.

DUARTE, P. Lula cobra internacionalização do BB e sugere novas aquisições de bancos. $O$ Globo, Rio de Janeiro, 21/07/2009. Disponível em: <http://www.fazenda.gov.br/resenhaeletronica/MostraMateria.asp?page $=\& \operatorname{cod}=568302>$. Acesso em: 21 jun. 2010.

DYMSKI, G. The Bank Merger Wave: the economic causes and social consequences of financial consolidation. New York: Sharpe, 1999.

EICHENGREEN, B. Global imbalances and the lesson of bretton woods. NBER Working Paper, n. 10497, 2004. Disponível em: <www.nber.org/papers/w10497>. Acesso em: 25 abr. 2008.

FOCARELLI, D.; POZZOLO, A. F. The determinants of cross-border bank share holdings: an analysis with bank-level data from OECD countries. Temi di Discussione, Banca Itália, Servizio di Studi, n. 381, 2000.

GALBRAITH, J. Crise na Europa: solução dos bancos é destruir os mais fracos. [On-line] Opera Mundi, 20/11/2011. Disponível em: <http://operamundi.uol.com.br/conteudo/opiniao/17979/crise+na+europa+solucao+dos+bancos+e+destruir+os+fracos.shtml $>$. Acesso em: 29 nov. 2011.

GERMIDIS, D.; MICHALET, C. International banks and financial markets in developing countries. Paris: OCDE, 1984

GRUBEL, H. The theory of multinational banking. Banca Nazionale del Lavoro Quarterly Review, n. 123, p. 349-363, 1977

HALE, G. Evidence on financial globalization and crisis: capital raising. Work Paper Series, Federal Reserve Bank of San Francisco, n. 2011-04, 2011.

ISTO É DINHEIRO. EUA: reduz o número de bancos em dificuldades (FDIC). Isto É Dinheiro, 22/11/2011. Disponível em: $<$ http://www.istoedinheiro.com.br/noticias/financas/20111122/ eua-reduz-numero-bancos-dificuldades-fdic/64881.shtml>. Acesso em: 29 nov. 2011

ITAÚ/UNIBANCO. Associação entre Itaú e Unibanco cria um dos maiores bancos do hemisfério sul. [On-line] Itaú/Unibanco, 2010. Disponível em: $<$ http://ww13.itau.com.br/PortalRI/ HTML/port/conheca/historiafusao.htm?AspxAutoDetectCookieSupport=1>. Acesso em: 25 fev. 2010.

ITAÚ/UNIBANCO. Relação com os investidores. Abrangência no exterior. [On-line] Itaú/Unibanco, 2012. Disponível em: <http://ww13.itau.com.br/portalri/index.aspx?idioma=port $>$. Acesso em: 02 jan. 2012.

KINDLEBERGER, C. P. American business abroad: six lectures on direct investment. New Haven: Yale University Press, 1969.

KRUGMAN, P. Exchange rates and wages. The New York Times, 24/12/2011. Disponível em: $<$ http://krugman.blogs.nytimes.com/2011/12/24/exchange-rates-and-wages/>. Acesso em: 28 dez. 2011.

LAGUNA, E. Bradesco: ida ao México não significa internacionalização. Valor Econômico. São Paulo, 17/08/2010. Disponível em: <http://www.valoronline.com.br/online/bancos/29/303291/internacionalizacao-volta-ao-foco-do-itau>. Acesso em: 25 jan. 2011.
MACARINI, J. P. A política bancária do regime militar: o projeto do conglomerado (1967 1973). Textos para Discussão, IE-UNICAMP, n. 124, jan. 2007.

MICCO, A.; PANIZZA, U. YEYATI, E. State-owned banks: they promote or depress financia development and economic growth? In: IABD Conference on Public Banks in Latin America: Myths and Reality, 25 fev. 2005. Disponível em: <www.iadb.org/res/publications/pubfiles/ pubS-491.pdf $>$. Acesso em: 29 dez. 2009.

MISHKIN, F. S. Financial consolidation: dangers and opportunities. NBER Working Paper, $\mathrm{n}$ 6655, 1998. Disponível em: <www.nber.org/papers/w6655>. Acesso em: 20 jun. 2010.

MODÉ, L.; SILVEIRA JUNIOR, A. Banco do Brasil compra banco de pequeno porte nos EUA. O Estado de São Paulo, 26/04/2011. Disponível em <http://www.estadao.com.br/noticias/ impresso,bb-compra-banco-de-pequeno-porte-nos-eua,710741,0.htm $>$. Acesso em: 25 jan. 2012

PAULA, L. F. The determinants of the entry of foreign banks in Brazil. In: Congresso Brasileiro de História Econômica, 5, e Conferência Internacional de História de Empresas ABPHE, 6 Caxambu, MG, 7-10 set. 2003.

PAULA, L. F.; ALVES JR, A. The determinants and effects of foreign bank entry in Argentina and brazil: a comparative analysis. Investigación Económica, v. 66, n. 259, p. 65-104, jan./ mar. 2007

REIS, J. G. A · VALADARES, S. M. Reforma do sistema financeiro do Brasil: implementação recente e perspectivas. Serie de Estudos Econômicos e Sociais, Banco Interamericano de Desenvolvimento, mar. 2004. Disponível em: <http://idbdocs.iadb.org/wsdocs/getdocument aspx?docnum $=355463>$. Acesso em: 21 out. 2010 .

RICH, G.; WALTER, C. The future of universal banking. Cato Journal, Washington, v. 13, n. 2 p. 289-313, 1993.

ROCHA, F. A. S. Desnacionalização bancária no Brasil (1997 - 2000). Dissertação de Mestrado, Instituto de Economia, Universidade Estadual de Campinas, Campinas, 2002.

SALLES, Y. Itaú e Unibanco planejam ser banco internacional em cinco anos. Folha de São Paulo, 03/11/2008. Disponível em: <http://www1.folha.uol.com.br/folha/dinheiro/ ult91u463648.shtml $>$. Acesso em: 20 jun. 2010

SEBASTIÁN, M.; HERNANSANZ, C. The Spanish banks strategy in Latin America. Vienna: Société Universitaire Européenne de Recherches Financières, 2000. Disponível em: <http:// econpapers.repec.org/scripts/redir pf? $\mathrm{u}=\mathrm{http} \% 3 \mathrm{~A} \% 2 \mathrm{~F} \% 2 \mathrm{Fwww}$.suerf.org\%2Fdownload\% 2Fstudies\%2Fstudy9.pdf;h=repec:erf:erfstu:9>. Acesso em: 20 jan. 2011.

SINDICATO DOS EMPREGADOS DOS ESTABELECIMENTOS BANCÁRIOS (SEEB). Internacionalização dos bancos brasileiros. Florianópolis: SEEB, 06/01/2010. Disponível em: $<\mathrm{http}: / /$ www.seebfloripa.com.br/index.php?option=com_content\&view=article\&id=687:b ancos-brasileiros\&catid=79:economia $>$. Acesso em: 04 abr. 2010 .

SILVA JUNIOR, A. Crise externa afeta plano de internacionalização do BB. O Estado de São Paulo, 22/09/2011. Disponível em: <http://economia.estadao.com.br/noticias/negocios+ geral,crise-externa-afeta-plano-de-internacionalizacao-do-bb,85240,0.htm>. Acesso em: 11 jan. 2012. 
STIGLITZ, J. E. Europe's Austerity Zombies. Project Syndicate, 26/09/2014. Disponivel em:< http://www.project-syndicate.org/print/joseph-e--stiglitz-wonders-why-eu-leaders-are-nursing-a-dead-theory>. Acesso em: 05 nov. 2014

STUDART, R. Investment in economic development. Londres e New York: Routledge, 1995. 